\title{
O CÓDIGO DOS INDÍGENAS: A INSCRIÇÃO DA NATIVA E A RAZÃO ETNOLÓGICA EM MOÇAMBIQUE $^{1}$
}

\author{
Osmundo Pinho*
}

\begin{abstract}
RESUMO
Nesse artigo, o autor discute o processo de elaboração do Código Penal e Civil dos Indígenas de Moçambique, a partir de determinados registros, fragmentos de uma documentação, encontrados no Fundo "Direção de Serviços de Negócios Indígenas", do Arquivo Histórico de Moçambique (AHM). Por meio dessa discussão busca enfatizar o processo de efetiva inscrição da nativa, como o descreve G. Spivak, sob o marco da "legibilidade", como discute de outra parte Veena Das. Ou, em outras palavras, o processo de extensão do Estado para suas margens ou a "estatização" da sociedade, por meio da produção da mulher "nativa" ou "indígena".

Palavras-chave: Moçambique; Estado; Indigenato; Colonialismo.
\end{abstract}

\begin{abstract}
In this article, I discuss the process of elaboration of the Penal and Civil I Code for the Indigenous of Mozambique. I do it by the reading of certain records, fragments of a documentation found in the Fund "Directorate
\end{abstract}

* Professor Adjunto no Centro de Artes, Humanidades e Letras da Universidade Federal do Recôncavo da Bahia, Cachoeira. Bolsista Estágio Sênior da CAPES no African and African Diaspora Department Studies da Universidade do Texas em Austin. Email - osmundopinho@uol.com.br

1 A pesquisa que fundamenta este trabalho foi apoiada pelo $\mathrm{CNPq}$, por meio dos editais MCT/CNPq/SPM-PR/MDA No 57/2008 e MCT/CNPq No 03/2009. Anteriormente o autor foi apoiado por meio de bolsa de Pós-Doutorado da FAPESP, desenvolvida junto ao departamento de Antropologia da UNICAMP, entre 2006 e 2008. Agradecemos a Sandra Chirinza, Abel Pemba e Alberto Calbe, pela preciosa ajuda no Arquivo Histórico de Moçambique. E a Isabel Casimiro e Tereza Cruz e Silva pelo apoio e sugestões em Maputo, onde também realizamos levantamento na Biblioteca do Centro de Estudos Africanos da Universidade Eduardo Mondlane. Obviamente a responsabilidade por quaisquer erros ou omissões é do autor. 
of Indigenous Affairs Services", in the Historical Archives of Mozambique (AHM). Through this discussion I seek to emphasize the process of effective inscription of the native, as G. Spivak describes, under the framework of "readability" as discussed elsewhere by Veena Das. Or, in other words, the process of extension of the State to its borders or "statization" of society, through the very production of the "native" or "indigenous" woman.

Keywords: Mozambique; State; Indigenate; Colonialism. 


\section{Introdução}

Por meu despacho de 28 de julho de 1941 (Boletim Oficial no. 32, 2a . Série) foi incumbido o Dr. José Gonçalves Cota de proceder Estudo Etnográfico das populações nativas da colônia a fim de elaborar os Códigos Penal e Civil dos indígenas em conformidade com o disposto no artigo $24^{\circ}$. do decreto no. 16:473. ${ }^{2}$.

Com essas palavras, o Governador-Geral de Moçambique, o General José Tristão de Bettencourt, cria a Missão Etognósica de Moçambique em 31 de Julho de 1941, para proceder à elaboração dos Códigos Penal e Civil dos Indígenas de Moçambique, a partir de estudo etnográfico dos povos da colônia. $\mathrm{O}$ trabalho foi entregue à chefia de José Gonçalves Cota, jurista e advogado da colôniaª

Nesse artigo, busco discutir a partir de determinados registros, fragmentos de uma documentação, encontrados no Fundo "Direção de Serviços de Negócios Indígenas", do Arquivo Histórico de Moçambique (AHM), o processo de efetiva inscrição da nativa, como o descreve G. Spivak ${ }^{4}$, sob o marco da "legibilidade", como discute de outra parte Veena Das 5 . Ou, em outras palavras o processo de extensão do Estado para suas margens ou a estatização da sociedade, nesse caso recaindo sobre o corpo da mulher "nativa" ou "indígena", justamente por meio da reconstituição dos debates que se referem ao

2 Processo 020811 direção dos serviços dos negócios indígenas S1/caixa 1640AHM - UEM.

3 SERRA, Carlos. Estado, pluralismo jurídico e recursos naturais recursos naturais. http://www.cfjj.org.mz/IMG/pdf/Microsoft_Word-trabalho_Pluralismo_Juridico_1_.pdf. 2010.

4 SPIVAK, Gayatri C. Crítica de la Razón Poscolonial. Madrid. Akal, 2010.

5 DAS, Veena. The Signature of the State: The Paradox of Illegibility. In. . DAS, Veena e POOLE, Deborah. Anthropology in the Margins of the State. School of American Research Press. Santa Fé. 2004. Pp. 225-252. 
conturbado processo de elaboração do referido Código Penal e Civil dos Indígenas de Moçambique, tarefa encomendada a Cota, pelo Governador $\mathrm{Geral}^{6}$ por meio do despacho acima referido.

Nesse sentido, primeiro discuto brevemente os impasses do pluralismo jurídico e da razão etnológica em Moçambique; em seguido apresento os atores e os termos da polemica em torno da elaboração dos códigos indígenas, com ênfase para as questões de gênero e parentesco; por fim aponto para algumas considerações teóricas ao final sobre a produção do estado como sua "marginalização" ou como a estatização da sociedade, por meio da incorporação do corpo da mulher como estratégia da "legibilidade" ou assujeitamento.

\section{Pluralismo Jurídico e Razão Etnológica}

Conforme observado em outras sociedades pós-revolucionárias, a refundação da normatividade jurídica é tarefa essencial para as nações pós-coloniais africanas. Em especial a relação entre o estatuto da mulher, do matrimônio, da herança e da filiação se revestem de importância fundamental, articulando a economia politica, a sexualidade e as relações de gênero e parentesco ${ }^{7}$. O estudo de Wendy Goldman que aborda os debates sobre a mulher e o casamento nos primeiros anos da revolução soviética mostra isso com clareza, para

6 Serra, 2010. Idem.

7 TRIPP, Aili Mari; CASIMIRO, Isabel; KWESIGA Joy; MUNGWA, Alice. African Women's Movements: Changing Political Landscapes Cambridge: Cambridge University Press, 2009. xvi + 263; ARNFRED, Signe. Sexuality and Gender Politics in Mozambique - Rethink Gender in Africa. Woodbridge. James Currey/The Nordic Africa Institute. 2011; OSÓRIO, Conceição e ARTHUR, Maria José. A Situação Legal das Mulheres em Moçambique e as Reformas Atualmente em Curso. Publicado originalmente em Outras Vozes. No. 1, outubro de 2002.; LAZREG, Marnia. Decolonizing Feminism. In . . OYÊWÙMÍ, O. (Ed.)African Gender Studies. A Reader. Palgrave. 2005. Pp. 68-80.; URDANG, Stephanie. Fighting Two Colonialisms. Women in Guinea-Bissau. New York. Monthly Review Press. 1979. 
um contexto tão distinto e tão análogo ao moçambicano, notadamente ao que se refere a "modernização" versus "tradição" camponesa. Para muito além dos anseios libertários, presentes na tradição socialista, a utopia emancipatória que deveria libertar a mulher do jugo masculino, aquela "primeira escravidão" a que se refere Engels, chocava-se segundo a autora com a dura realidade da dependência econômica da mulher e com as consequências desiguais da liberdade sexual para o sexos, na medida em que as medidas contraceptivas, por razões muito práticas e objetivas, históricas, não estavam disponíveis para as mulheres. Assim, a liberdade sexual, o "amor livre" e a igualdade erótica, que pareciam slogans de libertação para mulheres urbanas de classe média, produziam pesadas consequências para camponesas e trabalhadoras, notadamente no que se refere às relações de produção camponesas, baseadas na família patriarcal alargada. De tal forma, que tornou-se evidente a relação entre padrões de gênero e parentesco, e modos econômicos de reprodução social, recaindo sobre a mulher, sempre a carga mais pesada e os maiores ônus ${ }^{8}$.

No caso da sociedade moçambicana, em particular, tal debate se desenvolve contra o pano de fundo das culturas "tradicionais" ou contra o que ficou codificado como "usos e costumes", este constructo a um só tempo jurídico e etnológico ${ }^{9}$. E é nesse sentido que a consideração da "missão" de Cota ganha importância para entendermos como se definem os parâmetros para esse debate sobre a mulher, o casamento e a nova sociedade, no contexto pós-colonial, marcado mais por continuidades insuspeitas, do que por rupturas definitivas,

8 GOLDMAN, Wendy. Mulher, Estado e Revolução. Sao Paulo. Boitempo editorial. 2014; ENGELS, F., 2009, A Origem da Família, da Propriedade Privada e do Estado. São Paulo. Editora Escala; SACKS, Karen, 1975, "Engels Revisited: women, the Organization of Production, and Private Property”. In .__ REITER, Rayana R. (Ed.). Toward an Anthropology of Women. New York. Monthly Review Press: 211-234.

9 MACAGNO, Lorenzo, 2001, "O Discurso Colonial e a Fabricação de Usos e Costumes: Antonio Enes e "Geração de 95"”. In . . FRY, Peter (Org.). Moçambique Ensaios. Rio de Janeiro. Editora UFRJ: 61-90. 
com o sistema político-discursivo anterior. O imperativo politico de atrair para a esfera jurídica do Estado a regulação de gênero e das relações de parentesco parece, nesse sentido, um tarefa essencial para a construção do Estado e para sua reprodução marginal como "estatização" da sociedade ${ }^{10}$. De tal forma estruturante é o processo, que permanece, de modo diferido mas consistente, mesmo apos a independência em 1975. O processo iniciado sob os portugueses de legislar e regular, a mulher, seu corpo, seu sexualidade e as relações de parentesco, contra ou em relação aos modos "tradicionais" e suas práticas e crenças, "usos e costumes", permanecem e são ampliados sob o regime socialista e revolucionário da FRELIMO, ainda contra as modalidades culturais "primitivas" ou "retrógradas", como se observa na campanha contra o "lobolo", a poligamia, o levirato, etc. Ambas as etapas da "estatização" do corpo da mulher, colonial e pós-colonial, representam assim a coabitação da invenção do Estado e de determinada modernização da sociedade, através do corpo da mulher e de sua invenção como sujeito/assujeitado, legível por meio do aparato jurídico ${ }^{11}$. Surpreendentemente, entretanto a voz "relativista", que destoa dos colonialistas e socialistas se encarna na figura do jurista e etnólogo evolucionista, como veremos.

O debate sobre o pluralismo jurídico tem, evidentemente, grande importância em Moçambique, uma vez que ao longo do século XX diferentes sistemas jurídicos/costumeiros de regulação das relações sociais, e de arbitragem de conflitos, mais ou mesmos regulados pelo Estado, permaneceram como disjuntores da vida social da colônia/nação. Nas páginas da revista Justiça Popular, publicada entre 1980 e 1988 podemos acompanhar o intenso debate sobre a

${ }^{10}$ DAS, 2004. Idem. MBEMBE, Achile. On the Postcolony, University of California Press. 2001

${ }^{11}$ FOUCAULT, Michel, 2003b, A Verdade e as Formas Jurídicas. Rio de Janeiro. Nau Editora. STOLER, Ann Laura. Race and the Education of Desire. Foucault's History of Sexuality and The Colonial Order of Things. Durham and London. Duke University Press. 1995. 
transformação e aplicação da nova justiça revolucionária e os conflitos, tanto com a legislação portuguesa, e mais intensamente com os "usos e costumes", principalmente no que se refere ao parentesco e casamento.

É sob o registro de tais modulações, que a questão da mulher nativa, do casamento e do parentesco pode ser enquadrada, saltando das páginas da literatura antropológica para os códigos penais e civis. Ora, no período áureo do debate sobre pluralismo jurídico testemunhamos a rejeição ao "estudo etnográfico", identificado à etnologia como a produção (essencialização) da cultura, e na verdade como sua legitimação por meio da ciência relativista, exatamente como procede Cota. Tal essencialização aparece como fundamento pervertido dos pluralismos alimentados pela lógica de distinção política que, no "tempo colonial (....) procurava isolar e autonomizar os sistemas tradicionais como se existissem fora do processo histórico" (Justiça Popular, no. 5, 1982). Assim, é contra a etnologia, associada ao pluralismo jurídico colonial, que a FRELIMO se coloca.

O pluralismo relativista apresentava assim conexões com a culturalização da vida social, elemento importante da razão etnológica, que em associação ao poder colonial, produziu o indígena ou nativo $^{12}$. Dessa forma, a racialização (culturalização) africana caminhou pari passu às estratégias de dominação política e à elaboração de um arcabouço jurídico conceitual, capaz de conferir inteligibilidade aos processos administrativos, associando a diferença cultural à diferença racial como instrumento político de dominação. A "razão etnológica" operou pela invenção de grupos étnicos como um resultado articulado do esforço conjunto da administração colonial e de etnólogos, definindo as sociedades humanas como espécies diferentes, individualizadas, na tradição culturalista de Boas, ou por meio da ênfase comparativa, que associa o etnólogo comparatista ao colecionador

${ }^{12}$ MACAGNO, 2001. Idem. AMSELLE, Jean-Loup, 1998, Mestizo Logics. Anthropology of Identity in Africa and Elsewhere. Stanford. Stanford University Press. 
de borboletas, ou a etnologia a entomologia como o faz Junod ${ }^{13}$. De tal sorte, diz Amselle, que é a noção de comparativismo que funda a ideia de culturas africanas, substituindo unidades politicas organizadas em um continuum definido politicamente, por classificações culturais-naturais e tipologias ${ }^{14}$.

Em artigo publicado na Justiça Popular em 1981, “A Lei Muçulmana e a Lei Moçambicana - o Futuro dos usos e costumes", Albie Sachs, após entrevistar um ex-intérprete muçulmano do regime colonial, discute o Pluralismo Jurídico, para criticá-lo asperamente. O jurista associa o pluralismo aos regimes de discriminação que distinguem, por meio de divisões culturais, nativos e europeus. Em vez disso ele sustenta a necessidade da mais absoluta igualdade jurídica, o inverso do que ocorria, por exemplo, na África do Sul. Do mesmo modo, relembra a importância de atribuir-se direitos legais/ universais ao casamento para fins de herança e de descendência, não se distinguido assim, para fins jurídicos, os usos e os costumes. Todos os cidadãos moçambicanos, conclui, podem professar sua fé, mas perante o "tribunal popular revolucionário, serão meramente cidadãos moçambicanos".

É nesse mesmo sentido que, em 1982, Dagnino, Honwana e Sachs, comentam, nas páginas da "Justiça Popular":

O exercício das competências judiciais, usado como fonte de poder pelos chefes e indunas, desapareceu, os novos tribunais populares não baseiam suas decisões nos princípios do direito tradicional. Alguns dos seus aspectos tais como casamentos prematuros, a poligamia e o lobolo, são combatidos ao nível político e isso acontecerá até que a sociedade do campo produza necessariamente novas formas de relações familiares em conflito total com as concepções do direito tradicional. (Justiça Popular no. 5, 1982)

\footnotetext{
${ }^{13}$ JUNOD, Henri, 2009, Usos e Costumes dos Bantu. UNICAMP. IFCH. Campinas. ${ }^{14}$ AMSELLE, 1998. Idem.
} 
Ora, o pano de fundo para a incongruência jurídica que a FRELIMO imaginava erradicar, baseava-se na dualidade do direito nas colônias africanas, definida como efetiva dualidade do poder, encarnada no despotismo descentralizado, quer seja sob a modalidade da "indirect rule", ou do assimilacionismo "relativista" ${ }^{15}$. A distinção entre domínios jurídicos europeus e "nativos" alimentou dessa forma, não apenas a produção de distintos sujeitos do direito, do Estado e da Justiça, mas dois modos de normatização jurídica, um universal, europeu, e um outro particular, repetido entre as diversas modalidades "indígenas", e a esse último cumpria então superar-se.

No contexto histórico-político de Moçambique observamos assim um conflito de legalidade e sobreposição disciplinar. Que Boaventura de Souza Santos ${ }^{16}$ compreendeu justamente como determinada modalidade de pluralismo jurídico, e Mahmood Mamdani ${ }^{17}$ considerou como a herança dissimulada da dualidade do poder que, baseada na "razão etnológica", construiu um arcabouço heteróclito e híbrido para a regulação das práticas sociais e para a administração do poder. Como na opinião do sociólogo moçambicano Carlos Serra:

A codificação do direito costumeiro configurou-se, assim, como um mecanismo intencional de introdução gradual de transformações nos sistemas jurídicos das populações nativas, de modo a prosseguir a consolidação das relações de poder e dominação que caracterizam os estados coloniais e o controlo efectivo do território e das suas gentes por parte dos agentes da administração colonial (Serra, 2010: 27).

${ }^{15}$ MAMDANI, Mahmood, 1996, Citzen and Subject. Contemporary Arica and the Legacy of Late Colonialism. Princeton. Princeton University Press.

${ }^{16}$ SANTOS, Boaventura de Souza, 2003, "O Estado Heterogêneo e o Pluralismo Jurídico”. In. _. Conflito e Transformações Sociais. Uma Paisagem das Justiças em Moçambique. Porto. Edições Afrontamento: 47-95.

${ }^{17}$ MAMDANI. 1996.Idem. 
Ora, tendo em mente tais enquadramentos, estruturantes do contexto de interação/transformação dos sistemas jurídicos como sistemas de assujeitamento/regulação, consideraremos os documentos em análise.

\section{A Missão de José Cota}

O trabalho de Cota - após uma série de diatribes, dificuldades com intérpretes, disputas por combustível, fofocas e reclamações conclui-se em 1946, cinco anos depois de seu início com a publicação do "Projeto Definitivo do Código Penal dos indígenas da Colónia de Moçambique, acompanhado de um relatório e de um estudo sobre direito criminal indígena" e do "Projeto definitivo do estatuto do Direito Privado dos indígenas da Colónia de Moçambique, precedido de um estudo sumário do direito gentílico"18. Os materiais etnográficos que serviram de suporte à elaboração dos dois projetos, foram publicados anteriormente, em 1944, sob o título "Mitologia e Direito Consuetudinário dos Indígenas de Moçambique", acompanhado do muito significativo subtítulo "Estudo de Etnologia mandado elaborar pelo Governo Geral da Colónia de Moçambique”.

O ano de 1941, quando Cota inicia o trabalho, consta como inaugurando nova fase na administração colonial em Moçambique. No ano anterior, a Metrópole assistia a realização da Exposição do Mundo Português, o que proporcionou a ornamentação ideológica necessária à alteração da politica colonial. Teríamos assim, segundo Omar Ribeiro Thomaz, reunidas condições práticas e superestruturais - as exposições, os congressos, as disposições e regulamentações legislativas (o Ato Colonial, a Carta Orgânica do Império Colonial Português) — para um exercício efetivo de administração colonial ${ }^{19}$.

${ }_{18}$ Segundo Serra, estes nunca foram promulgados pelo Governo Metropolitano. (2010).

19 THOMAZ, Omar Ribeiro, 2002, Ecos do Atlântico Sul: Representações sobre o Terceiro Império Português. Rio de Janeiro. Editora UFRJ. ZAMPARONI, 
O esforço decidido para a consolidação da administração e do efetivo poder - colonial, seria o estabelecimento de uma nova normatividade jurídica para o exercício da função judicial colonial sobre os "indígenas" e, na verdade, a condição para a produção/ inscrição dos nativos no aparato político do Estado como atribuidor da legibilidade aos sujeitos coloniais.

A iniciativa encomendada a Cota, observaríamos, concordaria assim com um novo esforço para conceder coerência normativa aos distintos regimes jurídicos coabitantes na colônia, submetendo-as às prerrogativas do Estado Colonial Português.

\begin{abstract}
Nas colônias atender-se-a ao estado de evolução dos povos nativos, havendo estatutos especiais dos indígenas que estabeleçam para estes sob influência do direito público e provado português regimes jurídicos de contemporização com os seus usos e costumes individuais, domésticos e sociais que não sejam incompatíveis com a moral, com os ditames da humanidade ou com o livre exercício da soberania portuguesa, embora procurando o seu lento aperfeiçoamento. ${ }^{20}$
\end{abstract}

A linguagem utilizada por Cota nos documentos que pude consultar oscila entre apelos relativistas e uma fraseologia que remete ao velho evolucionismo antropológico. Estaria Gonçalves Cota em 1946 ainda excessivamente preso a uma abordagem de natureza evolucionista? Ainda que temperada com o particular relativismo/ assimilacionismo colonial? $\mathrm{O}$ anacronismo da abordagem seria uma questão relevante, uma vez que estaríamos nos anos 40 já sob a égide do funcionalismo britânico, vitorioso nas disputas no campo da teoria antropológica (Kuper, 1988). Ao citar, mais de uma vez,

Valdemir, 2007, De escravo a cozinheiro: colonialismo \& racismo em Moçambique. Salvador: Edufba. CABAÇO, José Luís, 2009, Moçambique. Identidade, Colonialismo e Libertação. São Paulo. Editora UNESP.

${ }^{20}$ Processo 020811 direção dos serviços dos negócios indígenas S1/caixa 1640AHM - UEM. 
Ancient Society (1877) de L. H Morgan, Cota parece dar testemunho de sua própria superação. $O$ fato de ser jurista e não antropólogo de formação, entretanto, o associa mais fortemente a genealogia evolucionista, e ao próprio Morgan, é claro, ele próprio também advogado (Kuper, 1988).

Adam Kuper nos lembra que a ênfase principal encontrada no evolucionismo esta fortemente associada a aspectos jurídicos, relativos à constituição do Estado, da família, da herança e da propriedade, elementos estruturantes da autopercepção e organização das sociedades capitalistas modernas na Europa: "Nor it is this altogether surprising, since the study of primitive society was not general regarded as branch of natural history. Rather it was treated initially as a branch of legal studies" (Kuper, 1988:3) ${ }^{21}$. Os povos considerados selvagens existentes à época, nos permitiriam reconstituir, na perspectiva evolucionista, a história da família humana, que é uma só em sua "fonte, experiência, progresso"22. Tal progresso seguiria uma linha unívoca, transitando do "direito materno" para o "direito paterno". Ideia canônica, compartilhada pelo inimigo de Cota, o Arcebispo de Lourenço Marques, Joaquim Teodósio: “O indígena, espontaneamente e em procura de estabilidade para o seu lar e de segurança para si e sua prole, vai abandonando o regime matriarcal e preferindo o patriarcal". ${ }^{23}$

${ }^{21}$ KUPER, Adam, 1988, The Invention of Primitive Society. London and New York. Routledge.

${ }^{22}$ MORGAN, Lewis Henry, 2005, “A Sociedade Antiga”. In. CASTRO,C. (Org.) Evolucionismo Cultural. Textos de Morgan, Tylor e Frazer. Rio de Janeiro. Jorge Zahar Editor.

${ }^{23}$ Processo 020811 direção dos serviços dos negócios indígenas S1/caixa 1640AHM - UEM. 
Na introdução a "Anthropology \& The Colonial Encounter" Talal $\mathrm{Asad}^{24}$ não nos deixa esquecer que o fato fundamental que permitiu o funcionalismo em África foi à dominação colonial, e em termos factuais, o Tratado de Berlim em 1884/1885, foi o evento geopolítico que desenhou as condições por meios das quais a representação da diferença etnográfica pode ser realizada em África ${ }^{25}$. Como é óbvio, de modo tão explicito quanto brilhante, na etnografia Nuer produzida por Evans-Pritchard ${ }^{26}$. Em seu ensaio no mesmo livro Asad ${ }^{27}$, insiste no compromisso do funcionalismo britânico em produzir uma miragem de sistemas sociais relativamente homogêneos e atemporais, por meio de sua inflexão teórica, imposição de uma temporalidade a-histórica aos nativos, agora posta em movimento pela presença colonial (Evans-Pritchard, 1993: 19) ${ }^{28}$. Entre as prerrogativas do evolucionismo jurídico e o quadro de referencias de funcionalismo colonial parecia então equilibrar-se o nosso Cota.

\section{A Oposição dos Bispos: O Antropólogo contra a Civilização}

O processo da pesquisa para elaboração do código e a sua própria aprovação pelas instâncias competentes revelam um mar de dificuldades e antagonismos, e nos permitem observar as contradições no interior do corpo principal do Aparato Colonial em Moçambique,

${ }^{24}$ ASAD, Talal (Ed.). Anthropology \& The Colonial Encounter. Amherst. Humanity Books. 1973.

${ }^{25}$ BRUNSCHWIG, Henri. A Partilha da África Negra. São Paulo. Perspectiva. 1993.

${ }^{26}$ EVANS-PRITCHARD, E. E. Os Nuer. São Paulo. Editora Perspectiva. 1993.

27 ASAD, Talal. Two Europeans Images of Non-European Rule. In. _ . Anthropology \& The Colonial Encounter. ASAD, Talal (Ed.). Amherst. Humanity Books. 1973. Pp. 103-120.

${ }^{28} \mathrm{O}$ trecho refere-se à dificuldade Evans-Pritchard extrair informações dos nuer, que haviam sido recentemente pacificados pela Royal Air Force. 
o Governo Geral, a Direção de Negócios Indígenas e as dioceses de Lourenço Marques e da Beira. O conjunto de agentes, representantes dessas instituições, envolve-se em interessante disputa - sobre a qual ainda muito a ser levantado - em torno da elaboração do código Civil e Penal dos indígenas de Moçambique, como veremos.

O material encomendado a Cota foi submetido ao escrutino do Tribunal de Relação da Colônia, que entendeu por bem ouvir o parecer dos Bispos de Lourenco Marques e da Beira, sobre o teor e mérito da codificação proposta. "A bem da Nação" transita então, entre as instâncias, o material etnológico, transmutada em código pelo jurista/etnólogo. Em 26 de novembro de 1947, D. Sebastião Soares, Bispo da Beira e Nampula, devolve a Direção dos Negócios Indígenas o copião do chamado "Estatuto do Direito Privado dos Indígenas De Moçambique”, que havia sido enviado à aquela repartição pelo "venerando" Tribunal da Relação de Lourenço Marques, a fim de que fossem ouvidas as missões católicas.

Os pareceres são terríveis, e frontalmente contrários ao trabalho de Cota. Fundamentalmente a legitimidade que a codificação parece oferecer aos costumes nativos perturba a autoconfiança e a consciência dos bispos que veem feridos os pruridos civilizatórios de que se julgavam avatares.

Entendendo que o código deve favorecer a "evolução natural do indígena para aproximar-se de nosso código civil", Dom Sebastião ataca em primeiro lugar o que se refere às instituições do casamento. Notadamente causava escândalo o relativismo de Cota, algo surpreendente em um suposto evolucionista: "Na página 70 diz-se que a poligamia e o lobolo podem ser mais verdadeiramente manifestações de uma civilização diferente da nossa do que sintomas de uma mentalidade baixa peculiar aos agregados selvagens". ${ }^{29}$

${ }^{29}$ Processo 020811 direção dos serviços dos negócios indígenas S1/caixa 1640AHM - UEM. 
Segundo o bispo tal afirmação é insustentável e "injustificável pela história, sobretudo pela nossa história". Feriria mortalmente a pretensão colonial portuguesa imaginar-se que costumes nativos pudessem equivaler às práticas civilizadas da metrópole.

A assentar em tais princípios códigos legislativos dos povos que ao dever de civilizar será preferível desistirem dessa empresa e por motivos de justificação pública ou confessar a nossa incapacidade de colonização ou então proclamar que os estados mais selvagens de quaisquer tribos são fases inconfundíveis da civilização. Neste caso a civilização perde o sentido que a história lhe consagra para ser apenas a manifestação viva dos povos, seja qual for à situação intelectual, moral ou social em que se encontrem. As tradições portuguesas ensinam que a civilização é coisa muito diferente. É esta uma questão fundamental por se tratar de princípios $^{30}$

Os princípios a que se refere o Bispo não podem estar à mercê das avaliações relativizantes, e a verdade da história, e a filosofia da história que parece invocada, não questiona a linearidade da evolução, muito menos o protagonismo dos povos europeus, o que Cota, aos olhos do bispo pareceria fazer.

Segue o bispo criticando ferozmente a poligamia, porque o etnógrafo buscando em certa altura preservar o direito da co-esposa, faz comentários sobre o fato do polígamo escorraçar as esposas que rejeita. Ora, se poligamia ela própria é inaceitável, como considerar o direito baseado num fato ilícito? Ademais sancionado por meio do lobolo $^{31}$, a famigerada compra da noiva?

${ }^{30}$ Idem.

${ }^{31}$ GRANJO, Paulo. Lobolo em Maputo: um velho idioma para novas vivências conjugais. Porto. Campo das Letras, 2005. PINHO, Osmundo. A Antropologia na Africa e o Lobolo no Sul de Mocambique. Afro-Asia. 43 (2011), 9-4. 
Outra enormidade! O pagamento do lobolo não supre os ritos nupciais que exprimem ou manifestam o consentimento mútuo; não pode, portanto, validar um casamento que era nulo por falta de consentimento. O que é mister é que o casamento cafreal seja celebrado segundo os ritos tradicionais ou na falta destes a Autoridade imponha a separação dos supostos cônjuges. ${ }^{32}$

O casamento legítimo é o matrimonio católico - uno, indissolúvel e perfeito e não uma mera "modalidade, ao lado do cafreal, maometano", etc., - nesse sentido o bispo pede que se elimine qualquer referência legitimadora à poligamia, simplesmente proibindo-a por lei.

Dom Joaquim Teodósio, Arcebispo de Lourenco Marques, havia anteriormente, em 31 de março de 1947, feito remeter à Direção de Negócios Indígenas o seu próprio parecer, no qual é muito claro: "Não concordamos com a finalidade do projecto nem com a doutrina exposta em muito dos seus artigos" uma vez que "dar foros de cidadania no domínio do direito a costumes bárbaros, parece-nos degradante para as nossas tradições de povo civilizado". ${ }^{33}$

A oposição do cardeal é semelhante à de seu colega da Beira, a legislação não pode incorporar ou mesmo legislar sobre o que deveria ser meramente extinto, como manifestação da missão civilizatória portuguesa e da vontade de Deus.

Pois é de estranhar que uma nação como a portuguesa que se constituiu desde há 8 séculos, a paladina da civilização cristã através do mundo - que recorda com título da sua mais lídima glória ter levado a civilização cristã a América, à Ásia, a Oceania e a África - que fixou na constituição como elementos fundamentais da educação moral as virtudes da doutrina e moral cristãs tradicionais do Pais (Arto. 420.) venha agora sancionar, codificando-os, os usos e costumes bárbaros da raça negra de Moçambique, como sejam a magia, as superstições pagãs, a poligamia, o lobolo, a iniciação ao casamento, etc. ${ }^{34}$

\footnotetext{
${ }^{32}$ Idem.

${ }^{33}$ Idem.

${ }^{34}$ Idem.
} 
Segundo o Cardeal, o decreto no. 35461 de 22 de janeiro de 1946, que regulamenta o casamento "canônico" entre os indígenas católicos, é claramente oposto ao projeto e deveria a ser a referência da legislação.

Neste caso também, e de modo retumbante, os argumentos da Santa Igreja se assemelham quase totalmente ao que posteriormente foram os argumentos de Samora Machel e da FRELIMO ${ }^{35}$. A família é a célula mater da sociedade, a base elementar sobre a qual se elevam e constroem os valores fundamentais da sociedade e da civilização. Cristianizando-se a família, diria o cardeal, teremos uma sociedade cristã. Ora, o casamento é a base da família, e por isso a "constituição familiar é tanto mais sólida quanto maiores garantias de unidade e indissolubilidade o casamento oferecer". ${ }^{36}$

Nas páginas da Revista "Justiça Popular", décadas depois, a FRELIMO repete o Bispo, na campanha pelo casamento civil, universal, que seria fundamental, dentre outras coisas, pela promoção da família (patriarcal, monogâmica, nuclear) como célula base da sociedade.

\begin{abstract}
Para construir uma sociedade nova temos que criar uma nova mentalidade no homem e na mulher, e este processo inicia-se no seio da própria família, célula-base de nossa sociedade. Embora o homem tenha o papel dominante, mas mulher, a esposa, a mãe assumem na família a grande responsabilidade de assegurar a estabilidade o lar e educar as novas gerações para o futuro (Machel, 1984). ${ }^{37}$
\end{abstract}

${ }^{35}$ MACHEL, Samora. A Libertação da Mulher é uma necessidade da Revolução, Garantia de sua Continuidade, Condição de seu Triunfo. Coleção Estudos e Orientações. Caderno No. 4. Edições da Frelimo. 1974 (1972). CEA - UEM. Pasta 161/W. CASIMIRO, Isabel Maria. Samora Machel e as Relações de Gênero. Estudos Moçambicanos. Número 21. Maputo 2005. Pp. 55-84.

${ }^{36}$ Idem.

${ }^{37}$ MACHEL, Samora. A Harmonia deve Começar no Seio da Cada Família. Presidente Samora na abertura da Conferência Extraordinária da OMM. CEA - UEM. Pasta 160/ZC. 1984. 
Desse ponto de vista, sustenta-se a importância do registro civil como fonte de informações e a necessidade de reconhecer-se, que a despeito da importância da família ampliada, o princípio a ser respeitado seria "o da voluntariedade por parte dos próprios cônjuges", o que vinte anos depois seria contemplado na Nova Lei de Família ${ }^{38}$. A família é, assim, entendida pela FRELIMO como a célula base de toda a sociedade, formada por meio do casamento, "união de um homem e de uma mulher", no que também concorda com o Cardeal Teodósio.

Em suma, vaticina o cardeal, Dr. Jose Lourenco Cota não sabe do que fala, e coloca em risco todo um projeto civilizatório: "Vê-se aqui que o autor não tem um conceito claro da civilização, admitindo como verdadeiras, civilizações até contraditórias." Pode haver, segue o prelado, e há na realidade civilizações mais ou menos perfeitas. "Mas há que admitir um critério absoluto de civilização; e este só pode basear-se na lei natural gravada pelo criador no coração dos homens, e aperfeiçoada pela moral cristã, do evangelho de Cristo". ${ }^{39}$ A lei natural de inspiração cristã, melhor desenvolvida na Europa que em África, deve ser cultivada e aprimorada como um dever. Desse ponto vista o código é inaceitável porque contraria o "fardo do homem branco" em África ${ }^{40}$.

${ }^{38}$ ARNFRED, 2011.idem. ARTHUR, Maria José. Ainda a Proposito da Lei de Família: Direitos Culturais e Direitos Humanos das Mulheres. Publicado originalmente em Outras Vozes. No. 4, agosto de 2003. OSÓRIO, Conceição e ARTHUR, Maria José. A Situação Legal das Mulheres em Moçambique e as Reformas Atualmente em Curso. Publicado originalmente em Outras Vozes. No. 1, outubro de 2002.

${ }^{39}$ Processo 020811 direção dos serviços dos negócios indígenas S1/caixa 1640AHM - UEM.

${ }^{40}$ O poema de R. Kipling diz: "Toma o fardo do homem branco/Envia o melhor de tua prole/Impõe o exílio a teus filhos/Para servir a necessidade do cativo/Para assistir, em pesada labuta,/A povos alvoroçados e incultos - /Indolentes raças que acabam de conquistar,/Mescla de demônio e criança"(1894). 


\section{Casamento, Divórcio, Poligamia}

As questões de parentesco e casamentos ocupam grande parte dos pareceres dos prelados coloniais, como estamos vendo. $\mathrm{O}$ Arcebispo refere-se em certa altura ao que Cota chama de cancro burocrático, implicado na dificuldade de reconhecimento do casamento "cafreal" e as complicações que adviriam da estipulação do pagamento do lobolo.

Nota sobre o lobolo. O que o autor diz nesta Nota sobre a natureza do lobolo, e se atendermos aos inúmeros e complicados litígios a que ele dá lugar na vida das famílias indígenas (págs. 126), parece-nos que seria de aconselhar a abolição pura e simples de semelhante uso cafreal. ${ }^{41}$

Ora, para o bispo estará na supressão pura e simples do lobolo, em todas as suas formas, a solução de tal "cancro burocrático". Tumor maior representaria a aprovação do divórcio, usual em diversas tradições culturais locais, notadamente no norte, mas perseguido como invenção do diabo pela igreja católica. Regulamenta-la, diz o Cardeal, equivaleria a legitimar o "amor livre!".

José Cota, entretanto, reage com vigor aos pareceres, defendendo o seu trabalho, em 10 de julho de 1947, no documento intitulado "Considerações sobre alguns pontos dos pareceres de sua eminência o cardeal arcebispo de Lourenço Marques e sua Excelência Reverendíssima o Bispo da Beira" ${ }^{42}$, remetido ao Capitão Furtado Montanha, da Direção de Negócios Indígenas. Cheio de falsa reverência, Cota refere-se com sutil ironia ao parecer:

${ }^{41}$ Processo 020811 direção dos serviços dos negócios indígenas S1/caixa 1640AHM - UEM.

42 Idem. 
Não vimos discutir alterações propostas por sua eminência o cardeal, ou por sua excelência reverendíssima o Bispo da Beira, ao projeto em questão, ditadas pelo seu modo especial de ver o problema da reforma social das populações nativas desta Colônia, nem tão pouco é nosso desígnio estabelecer aqui, fora do lugar e das boas regras, uma polêmica acerca de quaisquer pontos de vista pessoais com que não estejamos, porventura, em acordo, por motivos de ordem sociológica ou psicológica. ${ }^{43}$.

E logo busca desqualificar de uma só tacada o principal do argumento dos bispos. O Estatuto não é um código: "não há normas do direito imposto coativamente" e "não se pode consequentemente esperar da adoção deste regime jurídico a estagnação do direito tribal". Cota situa o seu trabalho como um documento de caráter "mais informativo que imperativo". Desse modo não se justificam as preocupações dos religiosos, de que o Estatuto estaria legitimando os costumes bárbaros dos indígenas, e impendido o trabalho de reforma social ou civilização, que seria o próprio fundamento da presença portuguesa em Moçambique. $\mathrm{O}$ estatuto teria o caráter útil de um material de consulta para administradores coloniais e a preocupação de Sua Eminência seria vã.

Entretanto, parece claro, que mesmo para o próprio Cota as coisas não seria tão inocentes assim, e ele compreendia muito bem que descrever com relativa isenção um conjunto de normas coerentes e sistemáticas de outros povos, equivaleria em grande medida a legitimá-las, justamente como criticaram posteriormente os juristas frelimistas. A própria produção de conhecimento sobre a sociedade colonial, no contexto daquele impudente assimilacionismo, implicaria uma transformação da decidida vontade de incorporar-se a regulação sobre a mulher e o casamento aos marcos da teologia cristã. $\mathrm{O}$ que, como vemos, de fato sucedia. O Estado, e sua racionalidade, buscavam regular, reduzir, apropriar-se do corpo da mulher e de sua alma/carne, de outro ponto de vista, mais prático que ideológico. Bus-

${ }^{43}$ Idem. 
cando esquivar-se de problema com a igreja, todavia, Cota diz: "No Paragrafo único deste artigo, indica-se expressamente o casamento canônico como a condição para se aplicar o direito civil português às questões sobre direito de família e sucessão".

Além do Lobolo, da poligamia e dos ritos de iniciação, a famigerada troca de esposas ganhou o seu quinhão de reprovação. Cota busca apaziguar os bispos: "Em coordenação com estes preceitos de morigeração da família e sublimação do direito tribal estabeleceram-se no código penal dos indígenas as sanções necessárias para o Ontamuene (troca de esposas) e para o casamento de inúbeis." E sugere penalidade no Art. 99. "Os indígenas casados segundo os ritos de sua tribo que emprestarem suas mulheres a outro homem ou as trocarem por outras mulheres casadas com os respectivos maridos, será punido com a pena de prisão correcional de até dois anos...". ${ }^{4}$

O nosso jurista ataca mais uma vez de relativista, dando uma no prego e outra na ferradura. Invoca a carta constitucional portuguesa de 1933 que teria a "contemporização" como um seu princípio. Assim, “mesmo Dr. Marcelo Caetano sábio professor de direito não ousou dar golpe mortal as tradições - O Estado português se propõe civilizar, mas também proteger a 'própria alma dos povos nativos da colônia"', 45

E, finalmente contra o argumento eclesiástico acerca da poligamia, Cota desenvolve a mais surpreendente argumentação, e com muita propriedade lembra aos envolvidos que a poligamia não é privativa dos povos "selvagens": "Se nossos olhos se voltarem para própria Europa civilizada poderão ver o doloroso espetáculo da poligamia ilegal..." E cita um fascinante caso histórico:

${ }^{44}$ Idem.

${ }^{45}$ Marcelo Caetano, eminente jurista, foi reitor da Universidade de Lisboa e Ministro das Colônias entre 1944 e 1947, e a partir de 1968, com o afastamento de Salazar, tornou-se em 1968 presidente do Conselho dos Ministros, onde permaneceu até Revolução dos Cravos em 1971, que pôs fim ao regime salazarista. 
Em 1848 foi apresentado a Câmara dos Deputados da França um projeto de estabelecimento da poligamia naquele país. $\mathrm{O}$ deputado proponente perguntava à Assembleia: 'Porquoi imnpose une seule femme a l'home, puisq'l peut procrér, chaque anné plusieurs enfants?'

Como era de se esperar tal proposta foi rejeitada por maioria. ${ }^{46}$ Tal manifestação diz Cota, implicaria em uma submersão atávica do homem em direção as seus traços primitivos. Em alguma medida demonstrando sua fidelidade ao evolucionismo, Cota acredita que a proposição francesa testemunharia o "desejo de regressão à ética do Homem primitivo das hordas amorais".

Mas ora, se a poligamia grassava na Europa a tal ponto de propor-se a sua legalização na França, pátria da civilização "como podemos nós acusar os negros da nossa colônia de bárbaros e imoralíssimos por manterem, no seio da sua vida social rudimentar, a poligamia, ao lado de outros costumes primitivos que são tudo o que resume e define a história das suas instituições e a sua psicologia?". E conclui hiper-relativista: "Se a civilização condescende com a hipocrisia e o amoralismo de homens casados (pois não os reprime como delito) a civilização deve, por maioria da razão, condescender, transitoriamente com a poligamia dos nativos". ${ }^{47}$

\section{A Mulher Nativa: Inscrição e Legibilidade}

Veena Das aponta como o Estado se impõe pelas possibilidades de sua imitação, mímica oblíqua de seu desempenho do poder. A relação entre o Estado, sua literatura, o corpus jurídico, digamos assim, e as performances orientadas pelo Estado produzem uma

\footnotetext{
${ }^{46}$ Processo 020811 direção dos serviços dos negócios indígenas S1/caixa 1640AHM - UEM.

47 Idem.
} 
distância, o "paradoxo da ilegibilidade", como o descreve a autora ${ }^{48}$. E que aparecem em casos concretos como contradições objetivas entre o aparato jurídico universal e os modos particulares das práticas culturais ou representações da "cultura"

A assinatura do Estado com uma força ilocucionária incorpora uma força "mágica" presença espectral, que opera como manifestação esvaziada repetida como mimese em suas margens. Refletindo-se como um espectro. Das argumenta que o Estado justamente se constrói em suas margens e nesses movimentos de tradução incompleta. "Through an exchange between the real and the imaginary as in notions of panic, and rumor, and credulity, the domain of the civil is instituted and controlled" (Das, 2004: 251). ${ }^{49}$

O romance "Ventos do Apocalipse" de Paulina Chiziane oferece uma fascinante imagem literária do pânico às margens do Estado:

Os chefes durante o dia apregoam a viva voz a ordem e o progresso, banindo os grupelhos supersticiosos e obscurantistas para não perder o emprego, mas quando chega à noite esquecem a doutrina do desenvolvimento sem Deus, e entregam-se com todo o fervor às preces do criador de todos os seres (Chiziane, 2010:60).

Neste caso em particular, como talvez tenha ficado claro, a produção do Estado em suas margens por meio dos poderes paradoxais da (i)legibilidade é também a produção de suas próprias margens, defendidas e diferidas no corpo dos nativos, e mais particularmente, no corpo das nativas. Nesse sentido, podemos considerar como Spivak, a necessidade do discurso universalizante da dominação colonial manifestar-se como a articulação de representações, e do poder da letra da lei em sua dimensão ilocucionária, como fundo último para a submissão das populações nativas,

\footnotetext{
${ }^{48}$ DAS, 2004. Idem.

49 Ibidem.
} 
por meio de sua conversão em indígenas, como sujeitos, força de trabalho e mão-de-obra barata ${ }^{50}$.

Em “Crítica da La Razón Poscolonial” Spivak discute a relação entre a produção discursiva europeia e a axiomática do imperialismo (colonial). Ora, esse demanda, segundo seu argumento, produz em sua própria engenharia interna o "informante nativo", figura ao mesmo tempo produzida e negada, ou repudiada (foreclosed). Como um sujeito da razão etnológica inscrito no binarismo dos gêneros, como invenção da posição estrutural/universal necessária da mulher como elemento "mimético" do poder do Estado. Como ela enfatiza o informante nativo possui um nome de homem "que porta consigo el afecto que inaugura el ser humano" ${ }^{1}$, mas seria mais produtivo considerá-lo como assumindo uma inflexão de gênero, que tem uma marca de origem geopolítica. Suplementando a argumentação freudiana, Spivak argumenta que o mal-estar civilizacional que o autor alemão descreve escora um "rechazo", que serviu de defesa a missão civilizatória. O informante nativo "sin biografia" mas inscrito pela etnografia, é nesse sentido uma peça chave na retórica "gendered" do colonialismo ${ }^{52}$.

Enviado em 20 de agosto de 2015

Aprovado em 30 de outubro de 2015

\footnotetext{
50 Já sabemos como as relações de gênero nativas entram no calculo da manutenção/ substituição de mão de obra, transferindo para as atividades não incorporadas a lógicas da mercadoria, o trabalho agrícola, predominantemente feminino, a responsabilidade para com a reprodução biológica da força de trabalho em Moçambique, como discutido em First (1998). FIRST, Ruth. O Mineiro Moçambicano. Um Estudo sobre a Exportação de Mão de Obra em Inhambane. Maputo. Centro de Estudos Africanos. Maputo. 1998.

${ }^{51}$ Spivak, 2010: 17.

52 "Aunque la historia sea un gran relato, lo que sostengo es que la posición de sujeto del informante nativo, crucial, y sin embargo repudiada (foreclosed), esta también inscrita históricamente, por lo tanto, geopolíticamente" (Spivak, 2010: 334).
} 